\title{
Atividade in vitro de fluconazol e itraconazol em biofilmes de Candida albicans
}

\section{In vitro activity of fluconazole and itraconazole on candida albicans biofilms candida albicans}

DOI: $10.46814 / \operatorname{lajdv3n5-036}$

Recebimento dos originais: 01/05/2021

Aceitação para publicação: 31/06/2021

\section{Fernando Yano Abrão}

Mestre em Biologia da Relação Parasito Hospedeiro

Instituição de atuação atual: Faculdade Unida de Campinas

Endereço completo: Rua 234, No 371 Setor Coimbra, Goiânia - GO, Brasil

E-mail.yanobruce@gmail.com

\section{Núbia Pontes Pereira}

Mestre em Medicina Tropical e Saúde Pública

Instituição de atuação atual: Secretaria da Educação do Estado de Goiás, Superintendência de Ensino Médio. Avenida Quinta Avenida - até 600 - lado par Setor Leste Vila Nova

74643030 - Goiânia, GO - Brasil

E-mail.nubiapontes@hotmail.com

\section{Laís Carneiro Naziasene Lima Marreto}

Mestre em Biologia de Relação Parasito- Hospedeiro

Unidade Federal de Farmácia/Faculdade de Farmácia

Instituição de atuação atual: Universidade Federal de Goiás/ Faculdade de Farmácia Endereço completo Rua 240, esquina com a $5^{\mathrm{a}}$ Avenida, s/n $\mathrm{n}^{\circ}$ Setor Leste Universitário,

Setor Leste Universitário, Goiânia - GO, Brasil

E-mail: lucia@padrao.com.br

Daniel Teles Zatta

Mestre em Ciências Farmacêutica

Instituição de atuação atual: Faculdade Unida de Campinas

Endereço completo: Rua 234, No 371 Setor Coimbra, Goiânia - GO, Brasil

E-mail: dtzatta@gmail.com

\section{Jacqueline Campos Borba de Carvalho}

Doutorado em Agronomia Pela Universidade Federal de Goiás

Instituição de atuação atual: Faculdade Unida de Campinas

Endereço completo: Rua 234, N 371 Setor Coimbra, Goiânia - GO, Brasil

E-mail: jacquelinecamposcarvalho@gmail.com

\section{Pedro Henrique Hasimoto e Souza}

Médico Residente em Radiologia e Diagnóstico por Imagem do Hospital das Clínicas da

Faculdade de Medicina da Universidade de São Paulo

E-mail: luciaksouza@gmail.com 


\section{Lúcia Kioko Hasimoto e Souza}

Doutoro em Medicina Tropical e Saúde Pública

Instituição de atuação atual: Universidade Federal de Goiás/Instituto de Patologia Tropical e Saúde Pública

Endereço completo: R. 235, s/n. ${ }^{\circ}$, Setor Leste Universitário, Goiânia - GO, Brasil

E-mail: luciaksouza@gmail.com

\section{INTRODUÇÃO}

Fungos do gênero Candida fazem parte da microbiota do trato gastrointestinal e genitourinário e demais superfícies do homem. Alterações das barreiras teciduais, da própria microbiota ou da resposta imune promovem um desequilíbrio na relação hospedeiro-parasita, permitindo a invasão do microrganismo nos tecidos do hospedeiro, causando infecções denominadas de candidíases (DRAGO et al., 2000; CALDERONE e FRONZI, 2001; BERMAN e SUDBERY, 2002; JIN et al., 2004; SILVA et al., 2008; HASAN et al., 2009).

Candidíase representa a terceira causa de infecção nosocomial por todo mundo, sendo Candida albicans a espécie mais frequente (KUHN et al., 2002b). O aumento no número de hospedeiros suscetíveis, como pacientes submetidos a tratamentos imunossupressivos, uso prolongado de antibióticos de amplo espectro e uso de dispositivos implantados, como cateteres e sondas têm favorecido o aumento da prevalência desta infecção (MOLERO et al., 1998; CHANDRA et al., 2001b; RAMAGE et al., 2001a). O índice de mortalidade mesmo após o tratamento medicamentoso é alto, variando de 40 a 60\% (WARNOCK, 2007; SENEVIRATNE et al., 2008; BARNES, 2008).

C. albicans por fazer parte da microbiota normal humana, entra em contato comdispositivos implantados, tais como próteses, tubos endotraqueais e vários tipos de cateteres. Este contato com estas superfícies pode levar a formação de uma comunidade altamente estruturada que são envolvidos por uma matriz extracelular, denominada de biofilme (DOUGLAS, 2002; KOJIC e DAROUICHE, 2004; BLANKENSHIP e MITCHELL, 2006;

PIERCE et al., 2008). O biofilme de C. albicans é resultado da adesão a um material e formação de uma camada basal de células confluentes, que se dividem e produzem hifas compartimentalizadas, com projeções longas, tubulares que se entrelaçam na região superior do biofilme. Estas células são responsáveis pela liberação de uma matriz extracelular estável de substâncias poliméricas. Dessa forma é criado um micro-ambiente que protege as células, evitando que sejam lavadas e levadas de áreas com fluxo de líquidos, como boca, intestinos e vagina, além 
de promover resistência aos antibióticos e a invasão por células de defesa do sangue (SOLL, 2008). Em um último estágio, são produzidas células filhas menos aderidas, que podem se desprender do biofilme maduro (BORECKÁ-MELKUSOVÁ e BUJDAKOVA,2008), funcionando como um reservatório de células infectantes (RAMAGE et al., 2005) podendo ser responsável por septicemia no paciente (VINITHA e BALLAL, 2007).

Infecções associadas a biofilmes são de difícil tratamento uma vez que estas estruturas microbianas apresentam resistência, tanto aos antimicrobianos quanto aos mecanismos de defesa do hospedeiro (HAWSER e DOUGLAS, 1994; KUMAMOTO et al., 2002; KROM et al., 2007). Os derivados azólicos como o fluconazol e o itraconazol tem como mecanismo de ação a inibição da biossíntese do ergosterol pela interação com a enzima lanosterol demetilase, responsável pela conversão do lanosterol a ergosterol, componente essencial da membrana fúngica (WYNN et al., 2003). Segundo Kumamoto et al. (2002), células de C. albicans dispostas como biofilme são 100 vezes ou mais resistentes ao fluconazol em comparação às células planquitônicas (células não sesseis). O aumento da resistência ao fluconazol durante a maturação do biofilme parece estar associado com um decréscimosignificante no conteúdo total de ergosterol, devido o ergosterol ser o sítio de ação dos fármacos azólicos (MUKHERJEE et al., 2003 e PÉRMAN et al., 2008). Outra hipótese, para explicar a resistência de biofilmes aos antifúngicos, é a presença da matriz extracelular que teria a função de impedir a sua difusão para o interior da estrutura formada, e apenas acamada superficial do biofilme estaria exposta a dose letal do fármaco administrado (ALFATTANI e DOUGLAS, 2004).

$\mathrm{Na}$ maioria dos casos a estratégia mais efetiva para tratamento destas infecções pode ser a remoção do dispositivo contaminado pelo biofilme (DONLAN, 2001), o que pode ter sérias implicações como no caso de válvulas cardíacas, próteses articulares e válvulas do sistema nervoso central (KUHN et al., 2002b). Tais características tornam infecções relacionadas à formação de biofilmes de Candida um problema clínico crescente, tornando necessário novos estudos nesta área de pesquisa (RAMAGE et al., 2001b). Portanto, o entendimento sobre formação, desenvolvimento e suscetibilidade é indispensável para a elaboração de estratégias terapêuticas para o tratamento de infecções relacionadas aos biofilmes de Candida. 


\section{OBJETIVO}

Avaliar a cinética de formação de biofilmes de diferentes isolados Candida albicans e determinar a concentração inibitória mínima (CIM) do fluconazol e itraconazol sobre biofilmes e células planquitônicas por meio da determinação das concentrações inibitórias mínimas.

\section{METODOLOGIA}

\subsection{ISOLADOS}

Foram avaliados 10 isolados de C. albicans provenientes de diferentes fontes, como cateter (C180, C140), sangue (S157, S211), unha (U02, U15) e mucosas bucal (M02, M36) e vaginal (V58, V60). As cepas foram isoladas e identificadas segundo Kurtzman e Fell (1998) no Laboratório de Micologia do Instituto de Patologia Tropical e Saúde Pública da Universidade Federal de Goiás (IPTSP-UFG). C. parapsilosis ATCC 22019 e C. albicans ATCC 28367 foram usadas como controle.

\subsection{SUSCETIBILIDADE ANTIFÚNGICA IN VITRO PARA CÉLULAS PLANQUITÔNICAS}

Todas as leveduras foram submetidas ao teste de suscetibilidade através da técnica de microdiluição em caldo, de acordo com o protocolo M27-A3 do Clinical Laboratory Standard Institute (CLSI 2008), para determinar a CIM. Foram avaliados dois agentes antifúngicos: itraconazol (Johnson e Johnson) e fluconazol (Pfizer). O meio Roswell Park Memorial Institute (RPMI 1640), com 0,165 mol/L de tampão MOPS (ácidomorfolinopropanosulfônico) em pH 7,0 foi utilizado. Foram distribuídos a partir da $2^{\circ}$ coluna de cada placa de microtitulação, $100 \mu \mathrm{L}$ deste meio.

O inóculo foi preparado a partir de colônias de C. albicans cultivadas em ágar Sabouraud dextrose (ASD) por 24 horas a $35^{\circ} \mathrm{C}$. Uma suspensão foi preparada em salina na concentração de 1 x $10^{6}$ células $/ \mathrm{mL}$. Esta suspensão foi diluída a 1:50 em água destilada e a seguir, 1:20 emRPMI 1640 para se obter uma concentração de 0,5 a 2,5 x $10^{3}$ células $/ \mathrm{mL}$.

As concentrações dos antifúngicos avaliadas variaram de 0,031 a $16 \mu \mathrm{g} / \mathrm{mL}$ para o itraconazol e de 0,125 a $64 \mu \mathrm{g} / \mathrm{mL}$ para o fluconazol. Na primeira coluna das placas de microtitulação foram colocados $200 \mu \mathrm{L}$ do antifúngico com o dobro da concentração inicial desejada e a partir desta, foram realizadas diluições seriadas, caindo a concentração pela metade no decorrer da linha, utilizando meio de RPMI. 
Para a realização dos testes de suscetibilidade, adicionou-se $100 \mu \mathrm{L}$ do inóculo em cada orifício da placa, contendo o antifúngico diluído. Controles do meio de cultura, do agente antifúngico e do inoculo foram realizados em cada placa. Candida parapsilosis ATCC 22019 foi utilizada como controle. A representação esquemática do teste de suscetibilidade in vitro para fungos é demonstrada na figura 1.

Figura 1. Representação esquemática da realização do teste de suscetibilidade in vitro pelo método de microdiluição em caldo.

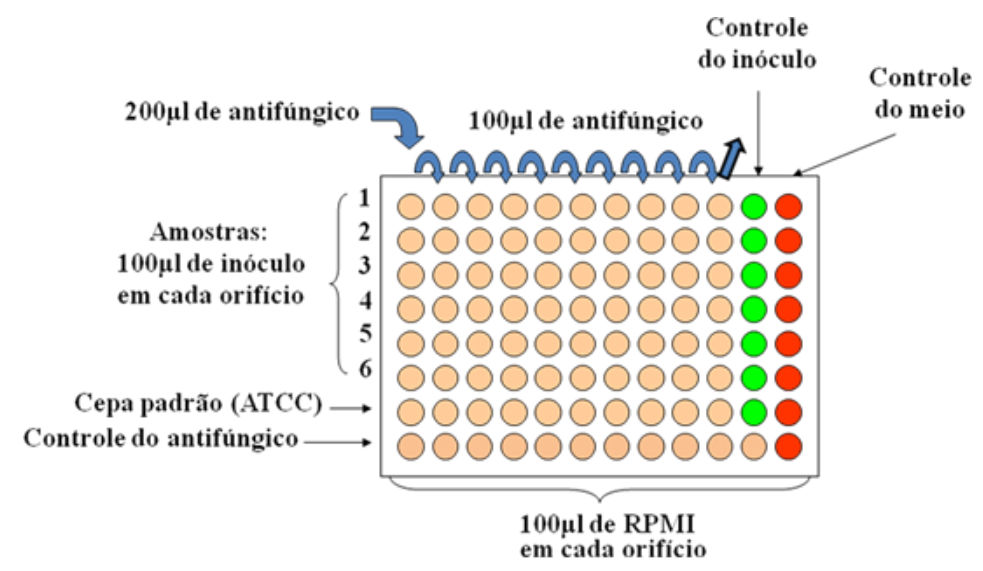

Para leitura dos resultados foi verificado o crescimento das leveduras, através da observação da turvação do meio, comparado ao controle de crescimento (livre de antifúngico). A CIM foi definida como a menor concentração capaz de inibir $80 \%$ docrescimento dos isolado de C. albicans, comparado com o controle.

Para a interpretação dos resultados os isolados com valores de CIM $\geq 1 \mu \mathrm{g} / \mathrm{mL}$ para itraconazol e $\geq 64 \mu \mathrm{g} / \mathrm{mL}$ para o fluconazol foram considerados como resistentes, seguindo valores preconizados no documento M27-A3 do CLSI (2008).

\subsection{FORMAÇÃO DO BIOFILME FÚNGICO}

A obtenção dos biofilmes de Candida foi realizada utilizando placas demicrotitulação de poliestireno, segundo metodologia descrita por Hawser e Douglas (1994) e Pierce et al. (2008), com modificações.

Para o preparo do inoculo, células de Candida provenientes de culturas em ASD (48 h) foram inoculadas em líquido YPD (extrato de levedura peptonado dextrosado) e incubadas “overnight” em agitador orbital a $30^{\circ} \mathrm{C}$. As células foram então centrifugadas a

$3.000 \mathrm{~g}$ por 5 minutos, o sobrenadante desprezado e o sedimento foi ressupenso em $10 \mathrm{~mL}$ de PBS estéril gelado, através de vigorosa agitação em vórtex, seguida de nova centrifugação. 
Ao precipitado final foi adicionado aproximadamente $2 \mathrm{~mL}$ de meio RPMI pré-aquecido a $37^{\circ} \mathrm{C}$ e foram realizadas diluições para ajustar a $85 \%$ transmitância a $530 \mathrm{~nm}\left(1,0\right.$ x $10^{6}$ células $\left./ \mathrm{mL}\right)$. Para a formação do biofilme, $100 \mu \mathrm{L}$ deste inoculo foi adicionado aos orifícios da placa de microtitulação.

A cinética de formação dos biofilmes foi realizada para diferentes períodos de incubação: 24 h, 48 h, 72 h e 96 h. Após a formação dos biofilmes, o meio foi aspirado e as células não aderidas foram removidas através da lavagem com PBS. A medida da atividade metabólica das células do biofilme formado foi avaliada utilizando-se o ensaio colorimétrico de redução de sais de tetrazólio, por 3-(4,5-Dimethyl-2-Thiazyl)-2,5-Diphenyl-2H- Tetrazolium bromide (MTT), que produz cristais formazan azul-escuros e insolúveis, no interior das células. A quantidade de cristais formados foi determinada espectrofotometricamente, através das leituras de densidade óptica (DO) em $550 \mathrm{~nm}$, servindocomo uma estimativa do número de mitocôndrias e consequentemente o número de células viáveis na amostra (FREIMOSER et al., 1999).

O MTT foi utilizado como uma solução de $0,5 \mathrm{~g} / \mathrm{L}$ em PBS, para cada $10 \mathrm{~mL}$ foi adicionado $1 \mu \mathrm{L}$ de solução de menadiona (10 $\mu \mathrm{M}$ acetona). Um volume de $100 \mu \mathrm{L}$ de MTT-menadiona foi então adicionado a cada orifício contendo o biofilme pré-lavado e também aos orifícios controle (sem biofilme). As placas foram então incubadas no escuro por 150 minutos a $37^{\circ} \mathrm{C}$ e após, o conteúdo dos orifícios foram descartados e adicionou-se em cada, $100 \mu \mathrm{L}$ de dimetilsulfóxido (DMSO), em agitação por 15 min, para a solubilização dos cristais formazan. A solução final de cada orifício foi transferida para novas placas e a presença de coloração foi medida a $550 \mathrm{~nm}$ em leitora de placas de ELISA (Behring).Pocinhos contendo DMSO foram utilizados como "branco" da reação. Os valores de DO obtidos do branco, foram subtraídos dos resultados obtidos das demais leituras e valores de DO maior ou igual a 0,200 foram considerados formadores de biofilme (VALENTÍN et al., 2007). Os valores de DO dos biofilmes formados individualmente, em quadruplicada, nos diferentes intervalos de tempo ( $24 \mathrm{~h}, 48 \mathrm{~h}, 72 \mathrm{~h}$ e $96 \mathrm{~h}$ ), foram comparados pelo teste ANOVA e pós-teste Tukey. Foi considerada diferença estatisticamente significativa quando $\mathrm{P}<0,05$. A análise foi feita com o programa SigmaStat versão 2.03 para Windows.

\subsection{TESTE DE SUSCETIBILIDADE ANTIFÚNGICA PARA BIOFILMES}

Os testes de suscetibilidade antifúngica dos biofilmes foram realizadas segundo Pierce et al. (2008). As concentrações dos antifúngicos avaliadas foram de 0,031 a $16 \mu \mathrm{g} / \mathrm{mL}$ para itraconazol e de 1 a $1.024 \mu \mathrm{g} / \mathrm{mL}$ para fluconazol. Aos biofilmes formados (48 h) foram adicionados $100 \mu \mathrm{L} \mathrm{de}$ 
cada concentração do antifúngico e incubados por $48 \mathrm{~h}$ a $37^{\circ} \mathrm{C}$. Os testes foram realizados em duplicata, sendo realizados concomitantemente controles de crescimento e esterilidade do meio.

As CIMs dos antifúgicos para os biofilmes foram definidas como as menores concentrações capazes de produzir reduções na DO igual a 50\% (CIMS50) e a 80\% (CIMS80), em comparação ao controle de crescimento (sem antifúngico).

\section{RESULTADOS}

A técnica de microdiluição em caldo permitiu obter valores de CIM para células planquitônicas de $C$. albicans de 1 a $8 \mu \mathrm{g} / \mathrm{mL}$ para o fluconazol e entre 0,0625 a $1 \mu \mathrm{g} / \mathrm{mL}$ para itraconazol. O isolado U02 mostrou com CIM igual a $1 \mu \mathrm{g} / \mathrm{mL}$ para o itraconazol, valor considerado resistente. Os valores das CIMs das células planquitônicas estão apresentados na tabela 1.

O estudo da cinética de formação dos biofilmes dos diferentes isolados de Candida mostrou que todos os isolados foram capazes de produzir biofilme $(\mathrm{DO} \geq 0,200)$ e que a atividade metabólica das células sésseis aumentou nas primeiras 48 h de incubação (Figura 4).

Os isolados M02 e U02 apresentaram as maiores atividades metabólicas, o que pode indicar uma maior produção de biofilme por parte destes isolados. O isolado V58 e a cepa padrão de $C$. albicans ATCC28367 mostraram uma maior atividade metabólica dos biofilmes com 24 h de formação. Por outro lado, para os demais isolados avaliados, os valores de DO obtidos no intervalo de $48 \mathrm{~h}$ apresentaram diferença estatisticamente significativa, quandocomparados com os obtidos nos demais intervalos de tempo $(\mathrm{P}<0,05)$.

Figura 2. Cinética de formação de biofilmes por isolados de Candida utilizando o ensaio colorimétrico (MTT), após a solubilização dos cristais formazan com DMSO, mostrando o aumento da atividade metabólica proporcional à intensidade da cor obtida.

Figura 3. Médias das DOs obtidas para todos os isolados de Candida sp. a cada intervalo de tempo (24 h, 48 h,72 h e $96 \mathrm{~h})$.

Figura2

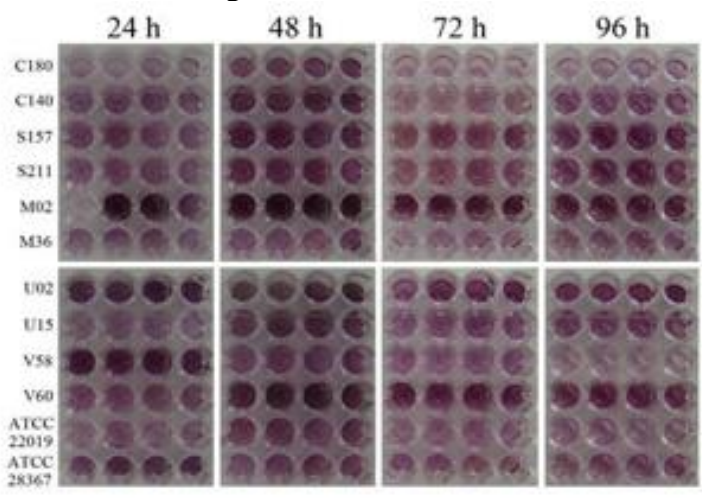

Figura3

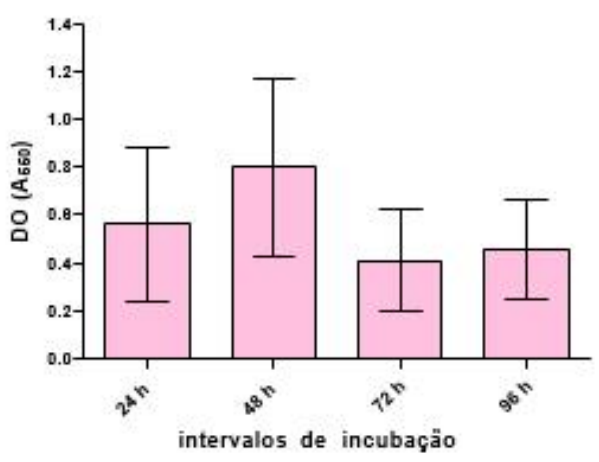


Os valores de DO obtidos com 24, 48, 72 e 96 horas de incubação variaram de 0,244 (U15) a 1,217 (M02); 0,433 (M36) a 1,541 (M02); 0,201 (C180) a 0,789 (M02) e de 0,140 (V58) a 0,813 (U02) respectivamente (Figura 4). A leitura das DOs dos isolados M02, U02 e V60 mostrou que as atividades metabólicas destes se destacaram em relação aos demais analisados, apresentando valores de DO > 1,237 com 48 h de incubação.

Figura 4. Avaliação da atividade metabólica de biofilmes formados por isolados de Candida sp. emdiferentes intervalos de tempo (horas), através da leitura de DO $(\lambda=550 \mathrm{~nm})$.

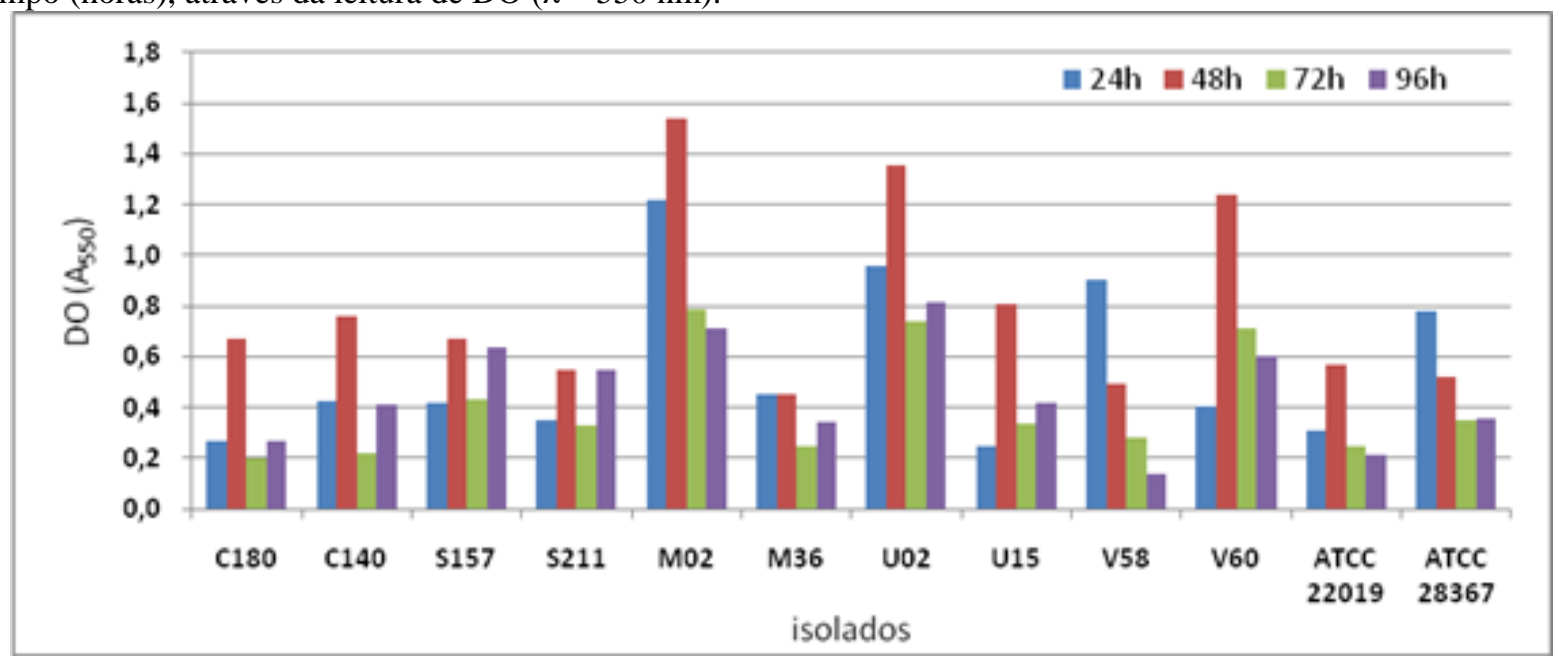

Tabela1. Valores de CIMP (células planquitônicas), CIMS50 e CIMS80 (biofilme) de diferentes isolados de Candida sp. para fluconazol e itraconazol.

$\operatorname{Resultados}(\mu \mathrm{g} / \mathrm{mL})$

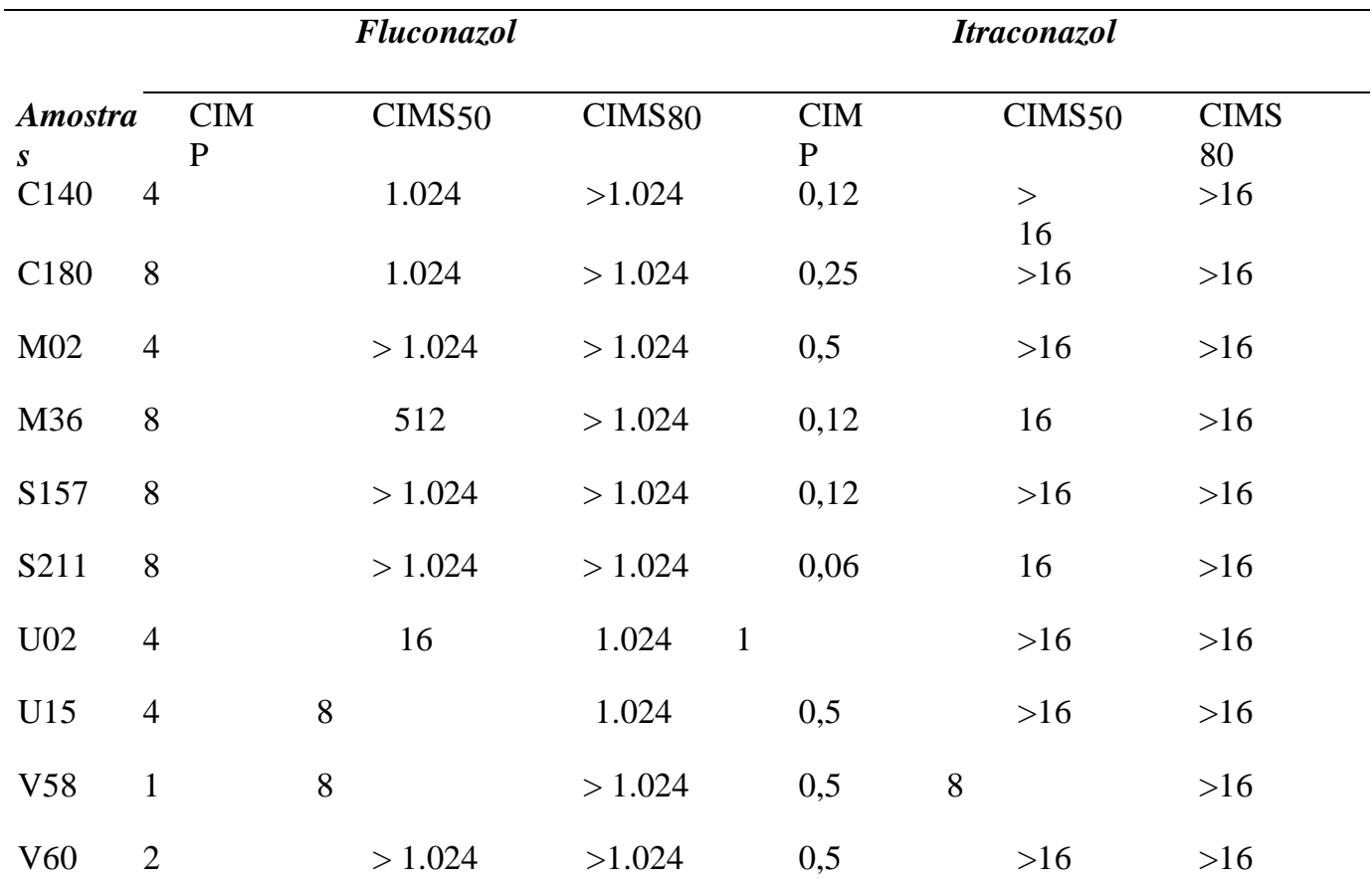




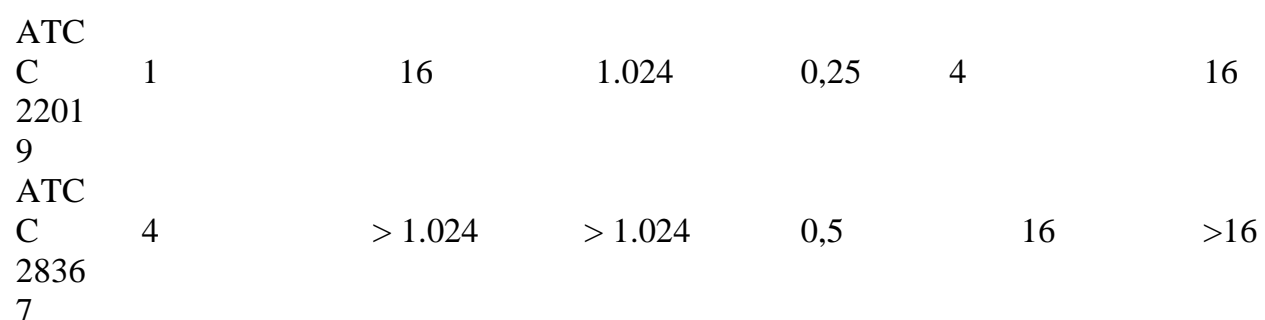

CIMP = concentração inibitória mínima de celulas planquitônicas; CIMS = concentração inibitória mínima decélulas sésseis (biofilme).

A avaliação da atividade in vitro dos antifúngicos fluconazol e itraconazol sobre biofilmes de C. albicans mostrou que para o fluconazol os valores obtidos para CIMS50 variaram de $8 \mu \mathrm{g} / \mathrm{mL}$ a $>1.024 \mu \mathrm{g} / \mathrm{mL}$ e para CIMS80 $\geq 1.024 \mu \mathrm{g} / \mathrm{mL}$. Com itraconazol a CIMS50 variou de $4 \mu \mathrm{g} / \mathrm{mL}$ a $>16 \mu \mathrm{g} / \mathrm{mL}$ e a CIMS $80 \geq 16 \mu \mathrm{g} / \mathrm{mL}$. Estes dados revelaram umaumento da CIMS50 e CIMS80 de fluconazol para os biofilmes, em comparação aos valores obtidos para células planquitônicas. Este antifúngico apresentou CIMS50 de $8 \mu \mathrm{g} / \mathrm{mL}$ para os isolados clínicos U15 e V58; de $16 \mu \mathrm{g} / \mathrm{mL}$ para o isolado clínico U02 e C. parapsilosis (ATCC 22019) e de $512 \mu \mathrm{g} / \mathrm{mL}$ para M36. Para os demais isolados os resultados foram iguais ou maiores que $1.024 \mu \mathrm{g} / \mathrm{mL}$. Os valores de CIMS80 foram todos $\geq 1.024 \mu \mathrm{g} / \mathrm{mL}$. Em relaçãoao itraconazol, os biofilmes formados pela maioria dos isolados apresentaram CIM50 eCIM80 $\geq 16 \mu \mathrm{g} / \mathrm{mL}$, resultados 40 vezes maiores do que o valor médio obtido para CIMP, quefoi de $0,39 \mu \mathrm{g} / \mathrm{mL}$. Entretanto uma redução de $50 \%$ da atividade metabólica pode ser percebida nos biofilmes dos isolados V58 e C. parapsilosis ATCCs, em concentrações abaixo de $16 \mu \mathrm{g} / \mathrm{mL}$ (tabela 1 ).

\section{DISCUSSÃO}

A observação de um aumento na incidência de isolados de C. albicans resistentes aos antifúngicos, como os derivados azólicos, pode ter como consequência um aumento na taxa de mortalidade de pacientes com candidíase, devido também a dificuldade no tratamento (MISHRA et al., 2007). Neste trabalho, a maioria dos isolados de C. albicans avaliados não foram resistentes ao fluconazol e itraconazol, quando submetidos ao teste de microdiluição em caldo para células planquitônicas. Apenas o isolado U02, foi resistente ao itraconazol, com CIM de $1 \mu \mathrm{g} / \mathrm{mL}$. Isolados de C. albicans resistentes a este antifúngico foi também observado por Carrillo-Muñoz et al. (2008), que obtiveram $1 \%$ dos isolados resistente ao avaliar 100 isolados clínicos através da técnica de disco difusão. Hawser et al. (1998), ao avaliarem a suscetibilidade de C. albicans ao itraconazol, através de ensaio colorimétrico por redução de sais de XTT e microdiluição em caldo, encontraram valores de CIM entre $0,125 \mu \mathrm{g} / \mathrm{mL}$ e $>16 \mu \mathrm{g} / \mathrm{mL}$. Entretanto, os isolados de $C$. albicans aqui avaliados 
apresentaram CIMs para itraconazol que variaram entre $0,0625 \mu \mathrm{g} / \mathrm{mL}$ e $1 \mu \mathrm{g} / \mathrm{mL}$, resultados próximos ao menor valor obtido pelo referido autor.

Ramage et al. (2001a) ao avaliarem a suscetibilidade antifúngica de isolados de C. albicans ao fluconazol, mostraram CIMs que variaram de 0,25 a $16 \mu \mathrm{g} / \mathrm{mL}$, semelhantes aos valores obtidos no presente trabalho (1 a $8 \mu \mathrm{g} / \mathrm{mL}$ ). Valores inferiores de CIM foram observados por Kuhn et al. (2002a) entre 0,25 a $1 \mu \mathrm{g} / \mathrm{mL}$. Os valores de atividade antifúngica obtidos para células planquitônicas, demonstram a eficácia do fluconazol no tratamento das infecções por Candida.

No estudo de cinética de formação, a maioria dos biofilmes produzidos pelosisolados de Candida apresentaram aumento da atividade metabólica até $48 \mathrm{~h}$ de crescimento e posterior decréscimo. Estes resultados foram semelhantes aos obtidos por Hawser e Douglas (1994) em experimento utilizando superfície de cateter, no qual observaram um crescimento máximo dos biofilmes de $C$. albicans até 48 h, com posterior declínio. Tal fato pode ser explicado devido à diminuição do oxigênio e dos nutrientes disponíveis no interior do biofilme. Acredita-se que a limitação de nutrientes no biofilme maduro possa levar à dispersão, mediada por comunicação intercelular, de células-filhas menos aderidas à matriz dobiofilme (UPPULURI et al., 2010).

A variabilidade intra e interespecífica em relação à capacidade de formação de biofilme por espécies de Candida são observadas em alguns estudos (VALENTÍN et al., 2007). Hasan et al. (2009) ao compararam a produção de biofilme entre espécies deCandida, isoladas de pacientes com candidemia, com C. albicans isoladas de lesões orofaringeanas de pacientes com AIDS, observaram que a formação de biofilme variousignificativamente entre espécies e entre isolados de C. albicans. No presente trabalho, todos os isolados avaliados mostraram capacidade de formar biofilmes, sendo observadas diferençasentre os isolados em cada um dos intervalos de incubação. Os isolados de C. albicans U02, M02 e V60 se destacaram quanto à atividade metabólica observada, principalmente, com 48 hde crescimento.

A resistência a alguns antifúngicos utilizados na terapia da candidíase está entre os fatores que contribuem para alta patogenicidade de Candida. Esta característica pode ser detectada através da realização dos testes de suscetibilidade in vitro (CHANDRA et al., 2001a; RAMAGE et al., 2001a). A técnica de microdiluição em caldo é adequada para avaliara concentração mínima do fármaco capaz de inibir o crescimento do fungo (CIM), se mostrando uma ferramenta importante para evitar o uso de uma terapia inadequada, em casos de resistência. Entretanto, os resultados produzidos por esta técnica não levam em consideração a resistência intrínseca exibida por culturas de células sésseis (biofilme), não havendo um método padronizado para tal avaliação (RAMAGE 
et al., 2001b). Uma associação de métodos (PIERCE et al., 2008; HAWSER e DOUGLAS, 1994) com utilização de placas de microtitulação de poliestireno nos permitiu uma análise semiquantitativa da atividade dos antifúngicos sobre os biofilmes, mediante ensaio colorimétrico com MTT, se apresentado como um método rápido, eficaz e reprodutível.

O teste de suscetibilidade antifúngica das células sésseis foi realizado sobre biofilmes de48 $\mathrm{h}$ de crescimento, intervalo de tempo no qual a maioria dos isolados apresentou maior atividade metabólica, verificada por meio de avaliação da redução de MTT. Segundo Pierce etal. 2008, entre 24 e 48 h de incubação, biofilmes de Candida apresentam arquitetura tridimensional característica, na forma de comunidades multicelulares, podendo ser utilizados em testes de suscetibilidade antifúngica.

Hawser e Douglas (1995) foram os primeiros avaliaram a suscetibilidadeantifúngica de anfotericina B, fluconazol, flucitocina, itraconazol e cetoconazol sobre biofilmes, utilizando discos de cateter. Os valores de CIMS80 obtidos foram muito superiores às necessárias para inibir o crescimento das células na forma planquitônica, confirmando desta forma a menor suscetibilidade de biofilme de Candida.

Pierce et al. (2008) em análise da suscetibilidade de biofilmes de isolados de C. albicans observaram valores de CIMS $80 \geq 1.024 \mu \mathrm{g} / \mathrm{mL}$ para fluconazol, semelhantes aos nossos, cujos resultados são 16 vezes maior que o valor considerado como resistentes de células planquitônicas. Entretanto, estes mesmos autores apresentaram valores de CIMS50 $\geq 1.024 \mu \mathrm{g} / \mathrm{mL}$, enquanto que em nossa avaliação, variaram entre 8 e $>1.024 \mu \mathrm{g} / \mathrm{mL}$.

O itraconazol não apresentou boa ação sobre os biofilmes formados por todos os isolados de Candida sp. Entretanto, a discussão destes resultados se torna difícil, uma vez que poucos trabalhos da atividade in vitro deste antifúngico sobre biofilmes de Candida são relatados.

A dificuldade no tratamento das candidíases em pacientes hospitalizados, especialmente aqueles que fazem uso de dispositivos médicos invasivos, levando a altas taxas de mortalidade, pode estar relacionada ao aumento da resistência de $C$. albicans sob a forma de biofilme, confirmados com este estudo. Assim, são necessários o desenvolvimento de novas substâncias antifúngicas capazes de agir efetivamente sobre biofilmes, assim como pesquisas de biomateriais a serem utilizados na fabricação dispositivos médicos invasivos, com características para prevenir a adesão inicial das leveduras. 


\section{CONCLUSÕES}

Os antifúngicos fluconazol e itraconazol mostraram atividade in vitro sobre todos os isolados de C. albicans, sob a forma planquitônica, apenas uma (U02) foi resistente ao itraconazol. Todos os isolados de Candida sp. foram capazes de formar biofilme nas primeiras 24 $\mathrm{h}$ de incubação, sendo que a maior atividade metabólica foi observada com 48 h de crescimento, indicando um maior número de células agregadas à estrutura, nesta fase considerada de maior maturação. Os resultados de CIM que inibiram 80\% (CIMS80) da atividade metabólica das células sésseis mostraram valores $\geq 16 \mu \mathrm{g} / \mathrm{mL}$ para itraconazol e $\geq$

$1.024 \mu \mathrm{g} / \mathrm{mL}$ para fluconazol, demonstrando a resistência dos biofilmes a estes antifúngicos. Estes resultados confirmam a dificuldade no tratamento de infecções associadas à formaçãode biofilmes de $C$. albicans associados a dispositivos médicos invasivos. 


\section{REFERÊNCIAS}

AL-FATTANI, M. A.; DOUGLAS L. J. Penetration of Candida biofilms by antifungal agents. Antimicrobial Agents and Chemotherapy 48(9):3291-3297. 2004.

BARNES, R. A. Early diagnosis of fungal infection in immunocompromised patients. J Antimicrob Chemother. 61(Suppl 1):i3-6. 2008.

BERMAN, J.; SUDBERY, P. E. Candida albicans: a molecular revolution built on lessons from budding yeast. Nature Reviews Genetics 3:918-930. 2002.

BLANKENSHIP, J.R.; MITCHELL, A.P. How to build a biofilm: a fungal perspective. Current Opinion in Microbiology 9:588-594. 2006.

BORECKÁ-MELKUSOVÁ, S.; BUJDAKOVA, H. Variation of cell surface hydrophobicity and biofilm formation among genotypes of Candida albicans and Candida dubliniensis under antifungal treatment. Can J Microbiol 54:718-724. 2008.

CALDERONE, R. A.; FRONZI, W. A. Virulence factors of Candida albicans. Trends Microb 9:327-335. 2001.

CARRILlO-MUÑOZ, A. J.; QUINDÓS, G.; DEL VALlE O.; SANTOS, P.; GIUSIANO, G.; EZKURRA, P. A.; ESTIVILL, M. D.; CASALS, J. B. Activity of caspofungin and voriconazole against clinical isolates of Candida and other medically important yeasts by the CLSI M-44A disk diffusion method with neo-sensitabs tablets. Chemotherapy 54:38-42. 2008.

CHANDRA, J.; KUHN, D. M.; MUCKHERJEE, P. K.; HOYER, L. L.; MCCORMICK, T.; GHANNOUM, M. A. Biofilm formation by the fungal pathogen Candida albicans: development, architecture and drug resistance. Journal of Bacteriology 183(18):5385-5394. 2001a.

CHANDRA, J.; MUKHERJEE, P. K.; LEIDICH, S. D.; FADDOUL, F. F.; HOYER, L. L.; DOUGLAS, L. J.; GHANNOUM, M. A. Antifungal resistance of Candidal biofilms formed on denture acrylic in vitro. J Dent Res 80(3):903-909.2001b.

Clinical and Laboratory Standards Institute (CLSI) 2008. Reference method for broth dilution antifungal susceptibility testing of yeast. Approved standard M27-A2. Clinical and Laboratory Standards Institute, Wayne, PA.

DOUGLAS, L. J. Medical importance of biofilms in Candida infections. Rev. Iberoam. Micol. 19:139-143, 2002.

DRAGO, L.; MOMBELLI, B.; VECCHI DE; BONACCORSO, C.; FASSINA, M.C.; GISMONDO, M. R. Candida albicans cellular internalization: a new pathogenic factor? Int J Antimic Agents 16:545-547. 2000.

FREIMOSER, F. M.; JAKOB, C. A.; AEBI, M.; TUOR, U. The MTT [3-(4,5-Dimethylthiazol-2-yl)2,5-diphenyltetrazolium bromide] assay is a fast and reliable method for colorimetric determination of fungal cell densities. Applied and environmental Microbiology 65(8):3727-3729. 1999. 
HASAN, F.; XESS, I.; WANG, X.; JAIN, N.; FRIES, B. C. Biofilm formation in clinical Candida isolates and its association with virulence. Microbes Infect 11(8-9):753-761. 2009.

HAWSER, S. P. e DOUGLAS, L. J. Biofilm formation by Candida species on the surface of catheter mateials in vitro. Infection and Immunity 62(3):915-21.1994.

HAWSER, S. P. e DOUGLAS, L. J. Resistance of Candida albicans biofilms to antifungal agents in vitro. Antimicrobial Agents and Chemotherapy 39(9):2128-2131. 1995.

HAWSER, S. P.; NORRIS, H.; JESSUP, C. J.; GHANNOUM, M. A. Comparison of a 2,3-Bis(2Methoxy-4-Nitro-5-Sulfophenyl)-5-[(Phenylamino)Carbonyl]-2H-Tetrazolium Hydroxide (XTT) Colorimetric Method with the Standardized National Committee for Clinical Laboratory Standards Method of Testing Clinical Yeast Isolates for Susceptibility to Antifungal Agents. Journal of ClinicalMicrobiology 36(5):1450-1452. 1998.

JIN, Y.; SAMARANAYAKE, L. P.; SAMARANAYAKE, Y.; YIP, H.K. Biofilm formation of Candida albicans is variably affected by saliva and dietary sugars. Arch Oral Biol. 49:789-798. 2004.

KOJIC, E. M. and DAROUICHE, R.O. Candida infections of medical devices. Clin. Microbiol. Rev. 17:255-267, 2004.

KROM, B. P.; COHEN, J. B.; FESER, G. E. M.; CIHLAR, R. L. Optimized Candidal biofilm microtiter assay. J Microb Meth. 68: 421-423. 2007.

KUHN, D. M.; CHANDRA, J.; MUKHERJEE, P. K.; GHANNOUM, M. A. Comparison of biofilms formed by Candida albicans and Candida parapsilosis on bioprosthetic surfaces. Infection and Immunity 70(2):878-888. 2002a.

KUHN, D. M.; GEORGE, H.; CHANDRA, J.; MUKHERJEE, P. K.; GHANNOUM, M. A. Antifungal susceptibility of Candida biofilms: Unique efficacy of amphotericin B lipid formulations and echinocandins. Antimicrobial Agents and Chemotherapy 46(6):1773-1780. $2002 b$.

KUMAMOTO, C.A. Candida biofilms. Current Opinion in Microbiology 5:608-611.2002.

KURTZMAN, C. P.; FELL, J. W. The Yeast, a Taxonomic Study, 4th ed., Elsevier, Amsterdam, Lausanne, New York, Oxford, Shannon, Singapure, Tokio, 420 pp. 1998.

MISHRA, N. N.; PRASAD, T.; SHARMA, N.; PAYASI, A.; PRASAD, R.; GUPTA, D. K.; SINGH, R. Pathogenicity and drug resistance in Candida albicans and other yeast species. Acta Microbiologica et Immunologica Hungarica 54(3):201-235. 2007.

MOLERO, G.; DÍEZ-OREJAS, R.; NAVARRO-GARCIA, F.; MONTEOLIVA L, P.L.A. J.; GIL, C.; SÁNCHEZ-PÉREZ, M.; NOMBELA. Candida albicans: genetics, dimorphism and pathogenicity. Internatl Microbiol. 1:95-106. 1998.

MUKHERJEE, P. K.; CHANDRA, J.; KUHN, D.M.; GHANNOUM, M. A. Mechanism of 
fluconazole resistance in Candida albicans biofilms: phase-specific role of efflux pumps and membrane sterols. Infect Immun. 71: 4333-40. 2003.

PÉRMAN, J.; CANTÓN, E.; VALENTIN, A. Actividad de la anidulafungina sobre biopelículas de Candida. Ver Iberoam Micol 25:124-128. 2008.

PIERCE, C. G.; UPPUlURI, P.; TRISTAN, A. R.; WORMLEY, J. R. F. L.; MOWAT, E.;

RAMAGE, G.; LOPEZ-RIBOT, J. L. A simple and reproducible 96-well plate-based method for the formation of fungal biofilms and its application to antifungal susceptibility testing. Nature protocols 3(9):1494-1500. 2008.

RAMAGE, G.; SAVILLE, S.P.; THOMAS, D.P. LÓPEZ-RIBOT, J. L. Candida biofilms: na update. Eukaryotic Cell. 4(4):633-638. 2005.

RAMAGE, G.; WALLE, K.V.; WICKES, B. L.; LÓPEZ-RIBOT, J. L. Standardized method for in vitro antifungal susceptibility testing of Candida albicans biofilms. Antimicrobial Agents and Chemotherapy 45(9):2475-2479. $2001 \mathrm{a}$.

RAMAGE, G.; WALLE, K. V.; WICKES, B. L.; LÓPEZ-RIBOT, J. L. Characteristics of biofilm formation by Candida albicans. Rev Iberoam Micol. 18:163-170. $2001 \mathrm{~b}$.

SOLL, D. R. Candida Biofilms: Is Adhesion Sexy? Current Biology 18(16): 717-720. 2008.

SENEVIRATNE, C. J.; JIN, L.; SAMARANAYAKE, L. P. Biofilm lifestyle of Candida: a mini review. Oral Dis. 14:582-590, 2008.

SILVA, W. J. D. A.; SENEVIRATNE, J.; PARAGHITIYAWA, N.; ROSA, E. A. R.; SAMARANAYAKE, L. P.; DEL CURY, A. A. Improvement of XTT assay performance for studies involving Candida albicans biofilms. Braz Dent J 19(4):364-369. 2008.

UPPULURI, P.; CHATURVEDI, A. K.; SRINIVASAN, A.; BANERJEE, M.; RAMASUBRAMANIAM, A. K.; KÖHLER, J. R.; KADOSH, D.; LOPEZ-RIBOT, J. L. Dispersion as na important step in the Candida albicans biofilme developmental Cycle. Plos Pathogens 6(3):1-13. 2010.

VALENTÍN, A.; CANTÓN, E.; PEMÁN, J.; QUINDÓS, G. Actividad in vitro de la anfotericina B yla anidulafungina sobre biopelículas de Candida albicans y Candida tropicalis. Ver Iberoam Micol 24:272-277. 2007.

VINITHA, M.; BALLAL, M. Biofilm as virulence marker in Candida isolated from blood. World Journal of Medical Sciences 2(1):46-48, 2007.

WARNOCK, D. W. Trends in the Epidemiology of Invasive Fungal Infections. Jpn. J. Med. Mycol. Vol. 48, 1-12,2007.

WYNN, R. L.; JABRA-RIZK, M. A.; MEILLER, T. F. Fungal drug resistance, biofilms, and new antifungals. Gen Dent. 51:94-8. 2003. 